\title{
SOBRE COMO MERGULHAR E FICAR DE CABEÇA ENXUTA: A REPRESENTACุÃO DO ESTRANGEIRO EM CONTOS GAUCHESCOS E LENDAS DO SUL
}

\author{
João Claudio Arendt ${ }^{73}$
}

RESUMO: Este artigo objetiva discutir a representação tanto do brasileiro (especialmente o carioca, o paulista e o baiano) quanto do estrangeiro (o açoriano, o português, o inglês, o alemão e, em especial, o castelhano e o espanhol) nas obras Contos gauchescos e Lendas do Sul, de João Simões Lopes Neto. A perspectiva assumida pelo autor, Simões Lopes, e seu narrador, Blau Nunes, é de critica a qualquer influência cultural oriunda do centro e do nordeste do país, e de franca oposição ao que provém do exterior, especialmente da Europa e da América hispânica. Para embasar a análise, recorre-se à historiografia, à crítica literária e a estudos sobre identidade.

Palavras-chave: Simões Lopes Neto; representação; identidade; estrangeiros

ABSTRACT: This paper aims to discuss the representation of Brazilian (especially from Rio de Janeiro, Sao Paulo and Bahia) as well as the foreigner (Azorean, Portuguese, English, German and, in particular Castilian and Spanish) in Contos Gauchescos and Lendas do Sul, written by João Simões Lopes Neto. The perspective taken by the author, Simoes Lopes, and narrator's voice, Blau Nunes, is critical to any cultural influence coming from the center and the northeast, and outright opposition to what comes from abroad, especially from Europe and Hispanic America. This work has as theoretical contribution the Historiography, Literary Criticism and Studies of Identity to support the analysis.

Keywords: Simoes Lopes Neto; representation; identity; foreigners

Tomando como ponto de partida a ideia de que a identidade é relacional, ou seja, que para existir ela depende de algo externo a ela, de uma identidade que ela não é, mas que fornece condições para que

73 Coordenador do Programa de Pós-Graduação em Letras, Cultura e Regionalidade da Universidade de Caxias do Sul (UCS) e do Programa de Doutorado em Letras - Associação Ampla UCS/Uniritter. Editor-chefe da Revista Antares: Letras e Humanidades. 
ela exista (Cf. WOODWARD, 2005), pode-se afirmar que a construção das identidades coletivas implica no estabelecimento de relações com os outros, a partir das quais se formam as imagens dos amigos e dos inimigos, dos aliados e dos rivais, dos "de dentro" e "dos de fora" de um determinado território ou grupo cultural.

No que diz respeito às manifestações literárias regionalistas, de um modo geral, observa-se que elas se baseiam na lógica da exclusão deliberada do outro, principalmente daquele que deve se situar fora dos limites geográficos de uma região. Conforme Jens Stüben (2002, p. 59), a literatura regionalista, de modo amplo, é aquela que "propaga a cultura de uma região como programa e paradigma, que lhe impõe limites em relação a outros espaços ou a defende contra um centro". Essa vertente da literatura costuma qualificar uma região com representações positivas das suas regionalidades, ou seja, das suas peculiaridades culturais. Entre suas intenções de natureza programática, estão, por exemplo, o desejo de preservar ou revalidar uma linguagem e hábitos em vias de extinção, impedir o avanço da mecanização e da indústria sobre as formas tradicionais de produção, erigir mitos de origem e exaltar os pioneiros ou fundadores da região, defender os valores naturais em oposição aos "artificiais”, lutar contra qualquer força alienígena que potencialmente ameace a região, etc.

No caso de Simões Lopes Neto, considerado pela crítica literária um dos principais autores regionalistas do Brasil, ergue-se "uma barreira quase intransponivel entre o território privilegiado do pampa e o que está situado além de suas fronteiras, distinguindo o gaúcho de todos os outros, inimigos ou forasteiros" (CHAVES, 1982, p. 14 - grifo original). Em Contos gauchescos e Lendas do Sul, é nítida a divisão maniqueísta da sociedade gaúcha entre "os de dentro" e "os de fora", conforme se lê já na abertura dos Contos gauchescos, onde o autor idealiza o território sul-rio-grandense e expõe o desejo de agrupar a coletividade em torno de seus valores culturais:

- Vi a colmeia e o curral; vi o pomar e o rebanho, vi a seara e as manufaturas; vi a serra, os rios, a campina e as cidades; e dos rostos e das auroras, de pássaros e de crianças, dos sulcos do arado, das águas e de tudo, estes olhos, pobres olhos condenados à morte, ao desaparecimento, guardarão na retina até o último milésimo da luz, a impressão da visão sublimada e 
consoladora: e o coração, quando faltar ao ritmo, arfará num último esto para que a raça que se está formando, aquilate, ame e glorifique os lugares e os homens dos nossos tempos heroicos, pela integração da Pátria comum, agora abençoada na paz (LOPES NETO, 1988, p. 33).

Pela voz do narrador, nota-se a presença de um suposto passado heroico, bem como a formação de uma nova "raça gaúcha" integrada à Pátria e abençoada na paz. Entretanto, diferentemente do que será visto mais adiante em relação aos estrangeiros, de modo especial os açorianos e platinos, o Rio Grande não se apresenta como um espaço hermeticamente fechado ao Brasil. No conto "Chasque do Imperador", por exemplo, o próprio Blau Nunes encarrega-se de contextualizar historicamente o evento, mostrando que, apesar da aparente diferença entre gaúchos e demais brasileiros, há momentos de integração entre ambos:

- Quando foi do cerco de Uruguaiana pelos paraguaios em 65 e o Imperador Pedro II veio cá, com toda a frota da sua comitiva, andei muito por esses meios, como vaqueano, como chasque, como confiança dele; era eu que encilhava-lhe o cavalo, que dormia atravessado na porta do quarto dele, que carregava os papéis dele e as armas dele (LOPES NETO, 1988, p. 71).

No contexto da guerra, o imperador é descrito como "homem alto, barbudo, ruivo, de olhos azuis, pequenos, mas mui macios", contrastando com o velho Caxias, "fardado e firme como sempre". Além disso, "o outro, o ruivo, assim a modo um gringo, vinha todo de preto, com um gabão de pano piloto, com veludo na gola e de botas russilhonas, sem esporas. Pela pinta devia ser mui maturrango ${ }^{74 "}$ (LOPES NETO, 1988, p. 71). A aparência fina e bem cuidada do imperador, com roupas estranhas, leva-o a ser caracterizado como um "gringo", ou seja, um estrangeiro em terras brasileiras. Além disso, ele falava "numa vozinha fina" (LOPES NETO, 1988, p. 72) e, por ter

${ }^{74}$ Segundo NUNES \& NUNES (1982), "maturrango" significa homem que monta mal. 
abraçado uma velha que visitava o acampamento, Blau tece o seguinte comentário: "esse era meio maricas, era!" (LOPES NETO, 1988, p. 74). O teor de deboche sobre os aspectos físicos e morais da figura monárquica distanciam-na dos atributos heroicos do gaúcho. Ainda nesses termos, há outra passagem no conto que deixa entrever certo antagonismo cultural entre os gaúchos e os habitantes da Corte, no Rio de Janeiro: “- Que vossa majestade está pensando?... Tudo isto é indiada coronilha, criada a apojo, churrasco e mate amargo... Não é como essa cuscada lá da Corte, que só bebe água e lambe a... barriga!..." (LOPES NETO, 1988, p. 73).

Levando em conta apenas esses dados, poder-se-ia inferir que a posição de Simões Lopes é contraditória, já que seus contos ora se abrem para uma integração, ora se fecham para diferenciar-se do Brasil. Nessa suposta contradição, há também uma assimilação do "gringo" da Corte, porque, enfarado com chás e doces e depois de grunhir fome, D. Pedro II acaba comendo um churrasco gaúcho. O que poderia ser, portanto, mera sacralização, acaba culminando em uma discreta dessacralização ${ }^{75}$, ou seja, uma desmistificação da figura do imperador: “- Quê! Pois vossa majestade come carne?! Disseram-me que as pessoas reais só se tratavam a bicos de rouxinóis e doces e pasteizinhos!... Por que não disse antes, senhor? Com trezentos diabos!... Ora esta!... Vamos já a um churrasco..." (LOPES NETO, 1988, p. 75). Tem-se a impressão de que ocorre uma súbita e importante descoberta: a de que o imperador é também de carne e osso, em grande medida igual ou semelhante aos gaúchos.

Ainda no mesmo conto, há uma tentativa de construir a imagem dos inimigos e dos amigos, dos rivais e dos aliados, a qual desempenha um importante papel na construção da identidade coletiva dos sul-rio-grandenses. O imperador e sua comitiva são classificados como aliados dos gaúchos, na luta contra os paraguaios, os quais, por seu turno, são vistos como rivais e inimigos a combater. O acontecimento histórico do cerco de Uruguaiana, em 1865, quando

\footnotetext{
75 De acordo com Zilá Bernd, em algumas manifestações literárias, "há a função de dessacralização, função de desmontagem das engrenagens de um sistema dado, de pôr a nu os mecanismos escondidos, de desmistificar. Há também uma função de sacralização, de união da comunidade em torno dos seus mitos, das suas crenças, de seu imaginário ou de sua ideologia" (BERND, 1992, p. 17 - grifos originais).
} 
da Guerra do Paraguai ${ }^{76}$, não pode ser entendido somente como um pretexto literário ou mero pano de fundo para o conto. Esse fato refere-se a um momento em que gaúchos e outros brasileiros defenderam a pátria contra o inimigo. E disso pode-se inferir a ideia de integração da Pátria comum, objetivada pelo escritor, na "Apresentação" de Contos gauchescos. Porém, o narrador não menciona a participação de argentinos e uruguaios que pela primeira vez, apesar da inimizade histórica com o Brasil, uniram-se a ele, sob a Tríplice Aliança, para derrotar Solano López.

Ao longo de Contos gauchescos, os estrangeiros, de um modo geral, vão sendo neutralizados, já que, segundo o narrador Blau Nunes, eles seriam os maiores responsáveis pela corrupção dos usos e costumes gaúchos. Tendo em vista que a construção da identidade se faz também pela exclusão, no conto “Deve um Queijo!...”, figura “um castelhano alto, gadelhudo, com uma pera enorme, que ele às vezes, por graça ou tenção reservada, costumava trançar, como para dar mote a algum dito, e ele retrucar, e, daí, nascer uma cruzada de facões, para divertir, ao primeiro coloreado..." (LOPES NETO, 1988, p. 59). E é esse castelhano que provoca o velho Lessa - "um homem assinzinho... nanico, retaco, ruivote" -, mas acaba levando a pior, tendo que se ir a la cria. Em outros termos, mesmo com seu bom porte físico e com o desejo iminente de provocar uma briga, ele não foi páreo para o vencedor, o velho e pequeno Lessa.

Ligia Chiappini observa que, em "Deve um Queijo", existe uma veia satírica que

[...] se volta para outro elemento de fora - eterno rival -, o castelhano que acaba saindo da história e do botecocenário, humilhado pelo velho Lessa, digno representante do gaúcho autêntico deste lado da fronteira. Mas a burla não é tanta que o gaúcho da outra banda deixe de ter a nossa simpatia, pelo seu atrevimento e petulância, atributos também muito gauchescos (CHIAPPINI, 1988, p. 378).

\footnotetext{
${ }^{76}$ A Guerra do Paraguai que se desenrolou entre 1865-1870 foi um conflito que uniu brasileiros, argentinos e uruguaios, na famosa Triplice Aliança, contra o ditador paraguaio Solano López, o qual pretendia ampliar o território de seu pais e, com isso, conquistar uma saida para o mar.
} 
O atrevimento e a petulância são também atributos do gaúcho, não tanto do herói, mas do herói degradado. Porém, é necessário levar em conta que a representação no texto em análise favorece claramente o gaúcho sul-rio-grandense, apresentando-o como vitorioso, em contraposição ao castelhano que, "de repente, empanzinado, de boca aberta, olhos arregalados, meio sufocado, todo se vomitando, pulou porta fora, se foi a um matungo e disparou para a barranca do passo... e foi-se, a la cria!..." (LOPES NETO, 1988, p. 61). E, para deixar bem clara a situação de inferioridade do castelhano, ele não só é gadelhudo, clinudo e perdedor, como seu cavalo também não passa de um "matungo". 77

Em "Correr eguada", novamente observa-se uma conduta distintiva do narrador em relação ao elemento estrangeiro. Primeiramente, o conto remete ao tempo em que "tudo era aberto; as estâncias pegavam umas nas outras sem cercas nem tapumes" (LOPES NETO, 1988, p. 67). O tempo das sesmarias, do gado chimarrão e da eguada xucra, orelhana que "era imundície, por esses campos de Deus; miles e miles". Época em que o homem vivia em suposta harmonia com o seu meio e ainda não se desenvolvera a comercialização de muitos produtos da atividade pastoril. Por isso, os animais eram mortos, conta Blau, para a limpeza dos campos. Entretanto, os estrangeiros são percebidos como responsáveis por trazerem o capitalismo e a consequente corrupção para os campos do Rio Grande: "[...] depois é que apareceram uns lamões e uns ingleses, melados, que compravam o cabelo: por isso às vezes se cerdeava; mas eles pagavam uma tuta e meia. Veja vancê: sempre a estrangeirada especulando coisas de que a gente nem fazia caso..." (LOPES NETO, 1988, p. 67 - grifo original). Os estrangeiros, conforme o narrador, teriam vindo especular coisas de que o gaúcho não fazia caso nenhum, como a eguada xucra, considerada uma erva daninha.

Na lenda "A Salamanca do Jarau", também se identifica crítica similar ao estrangeiro. Blau Nunes conta que "mouros e outros espanhóis renegados" atracaram no litoral gaúcho, trazendo a "cobiça de riquezas" à gente nativa desta terra "que só comia caça, o peixe, a fruta e as raízes que Tupã despejava sem conta, para todos, das suas mãos sempre abertas e fazedoras..." (LOPES NETO, 1988, p. 143). A

\footnotetext{
${ }^{77}$ Segundo NUNES \& NUNES (1982), o termo "matungo" designa um cavalo velho, ruim e imprestável.
} 
prática exploratória teria sido supostamente implantada no Rio Grande do Sul por volta de 1650 e vencida com grande sacrifício por Blau, o gaúcho de "alma forte e coração sereno", somente duzentos anos depois, pelos idos de 1850, ao entrar na furna encantada.

O conto "Melancia-Côco Verde", por sua vez, insere-se igualmente no cânone da rivalidade, da não aceitação do estrangeiro, já que Sia Talapa é obrigada pelo pai a casar com um primo, "um ilhéu mui comedor de verduras, e que para montar a cavalo havia de ser em petiço e isso mesmo o petiço havia de ser podre de manso..." (LOPES NETO, 1988, p. 88). A moça, contudo, esvaía-se em pranto só de pensar na desgraça daquele casamento, sobre o qual Blau se manifesta da seguinte maneira: "Era mesmo uma pena, lhe digo... casar uma brasileira mimosa ${ }^{78}$ com um pé-de-chumbo, como aquele desgraçado daquele ilhéu... só porque ele tinha um boliche em ponto grande!..." (LOPES NETO, 1988, p. 88).

O casamento arranjado pelo pai é unicamente por interesse, já que o ilhéu, por ser dono de um estabelecimento, garantiria o sustento da moça. A posição assumida pelo narrador tende para o lado de Costinha, que tinha uma "paixão braba" e correspondida por sia Talapa, mas que foi obrigado a partir para "uma gangolina com os castelhanos", à qual foi "dos primeiros a se apresentar" voluntariamente. Enquanto lutava heroicamente no campo de batalha, Costinha era atraiçoado através do conchavo entre o ilhéu e o pai da moça.

Tudo neste conto concorre para a descaracterização do elemento externo, o estrangeiro, em contraste com o elemento interno, o gaúcho: "O ilhéu às vezes vinha à estância do tio, em carretinha...; veja vancê como ele era ordinário, que nem se avexava de aparecer de carretinha, diante da moça!... E era só cama com lençóis de crivo, para o primo; fazia-se sopa de verdura para o meco; e até bacalhau aparecia, só para ele!..." (LOPES NETO, 1988, p. 88). Trata-se de um tipo étnico-social, segundo o narrador, indigno de casar com uma "brasileira mimosa" - além de que para o estrangeiro

\footnotetext{
${ }^{78}$ É interessante notar, à parte, a expressão "brasileira mimosa", que comprova a teoria de Ligia Chiappini (1988, p. 125) de que Simões Lopes Neto compartilha de ideais otimistas, "na crença de um Pais Novo, de uma nação concebida como um organismo em que se integram, harmoniosamente, os Estados". Sia Talapa, mesmo sendo gaúcha, não deixa de ser brasileira.
} 
"isto das nossas comidas", como churrasco escorrendo sangue e gordura, tripa grossa assada nas brasas, etc., "não valia nem um sabugo!..."

Apesar do seu discurso xenófobo, Blau não deixa de reconhecer, timidamente, a contribuição de reinóis e ilhéus para a economia gaúcha:

O que nós somos hoje a eles devemos? Qual! É verdade que uns inventaram a plantação de trigo... isso enfim, era bom...; sempre era uma fartura; noutras casas plantavam e fiavam linho... também não era mau, isso; noutras cardavam lã... Algum mais vivaracho botava tenda e vendia mechiflarias ou prendas de ouro... Nalguns trocava-se uns quantos couros por um pão de açúcar, e pipote de cana por qualquer meia dúzia de vacas. E sempre corria alguma dobla, de salário, e algum cruzado pela peonada de ajuste. Mas, como quera... eram mui entonados, os reinóis (LOPES NETO, 1988, p. 89).

Apesar da contribuição econômica, havia sempre, segundo Blau, alguns espertalhões que exploravam a gauchada, como na troca de vários couros por apenas um pão de açúcar, ou de meia dúzia de vacas por uma pipa de aguardente. Sob a óptica do narrador, transparece a ideia de uma terra rica em tais produtos e ainda não corrompida pelo processo mercantil de compra e venda. Porém, ela já apresentava elementos internamente nocivos.

$\mathrm{Na}$ opinião de Chiappini,

[...] ao tratar assim os homens da cidade, ou de outras zonas do Estado, não hegemônicas, Simões está, num certo nível, reproduzindo a ideologia dos fazendeiros gaúchos que, ao perceberem a concorrência do colono italiano ou alemão e do ilhéu comerciante, citadino, desmoralizam-nos exaltando os atributos do gaúcho tradicional. Mas essa leitura pode ter sua contrapartida pois, do ponto de vista do peão, as transformações da estância, por essa concorrência, e o desenvolvimento da cidade, com todas as consequências sociais e culturais, representaram perdas reais (CHIAPPINI, 1988, p. 318- 
319).

É principalmente durante a República Velha (1889-1930) que a discussão em torno das possiveis consequências econômicas para a Campanha, resultantes do apoio governamental à área geográfica dedicada à produção agrícola, torna-se acirrada. Com a proclamação da República, em 1889, houve a ascensão, em nível nacional, dos cafeicultores paulistas e dos militares, principais responsáveis pela queda da Monarquia. A economia brasileira dessa época sustentavase, de um modo geral, no dinamismo e no crescimento do setor cafeicultor de exportação. Desde o começo do século XIX, o café já era o principal produto da pauta das exportações brasileiras, atingindo mais de $50 \%$ na década que antecede a proclamação da República, o que caracteriza a economia da época como essencialmente monocultora (Cf. FONSECA, 1983, p. 17-18).

Se a lavoura cafeeira garantia a exportação brasileira, a economia gaúcha, por sua vez, especializava-se no abastecimento do mercado interno ou nacional, produzindo gêneros de primeira necessidade, consumidos, principalmente, no Sudeste do país. Pedro Dutra Fonseca, além de confirmar esses dados, acrescenta:

Durante o Império, a despeito das crises que seu principal produto, o charque, enfrentava, o Rio Grande pôde contar, senão sempre mas muitas vezes, com protecionismo. Neste sentido devem ser assinalados: a relativamente grande população local, capaz de dar acesso a cargos de representação política; a sua posição estratégica, principalmente nas guerras contra Oribes, Rosas, Aguirre e Solano Lopes; e, finalmente, sua própria posição econômica, fornecedora de gêneros às vezes essenciais para o consumo nacional (FONSECA, 1983, p. 17).

Esse protecionismo, ainda durante o Império, deve ser entendido dentro de uma estrutura econômica brasileira fragmentada, ou seja, com diversas economias independentes entre si, principalmente após a abolição da escravatura, ocorrida em 1888, único vínculo entre elas. 
Em consequência disso, ao ser proclamada a República (1889), a até então Província de São Pedro era dirigida por estancieiros e charqueadores, principais representantes da força econômica, unidos politicamente em torno do Partido Liberal. Opositores da República, os que não aderiram a ela foram depostos e, em seu lugar, assumiram os simpatizantes do Partido Republicano Rio-Grandense (PRR), até aquele momento inexpressivos na política local, além daqueles que aderiram ao novo regime político.

Essa substituição partidária gerou grande instabilidade política no Rio Grande do Sul. Se a República representava uma ruptura com o velho sistema monárquico que permitia a barganha e os favores a lideres locais da situação, era impossivel permitir que os liberais monarquistas se mantivessem no poder - embora esses representassem a facção mais autêntica das classes dominantes da Província -, contassem com um chefe de imensa simpatia e autoridade, e possuíssem as melhores reservas de influência e dinheiro (Cf. FRANCO, 1988).

Os conflitos ideológicos avançaram e, em 1893, estourou a Revolução Federalista, também conhecida como Revolução da Degola, tamanha a violência que ela assumiu. Entretanto, os republicanos conseguiram assumir o governo do Estado, posição que se manteve durante décadas, com breves interrupções e conflitos, como o de 1923, denominado Revolução Assisista.

É necessário ter presente, ainda, o fato de que o PRR conseguiu se manter no poder durante um longo período, apesar da oposição feita pelo Partido Liberal e por coalizões entre partidos. Os mecanismos empíricos, lícitos ou não, utilizados para tal, como, por exemplo, as fraudes eleitorais, a cooptação política e os abusos de poder, foram recursos largamente utilizados (Cf. FÉLIX, 1987).

A crise e a estagnação da economia pecuário-charqueadora da Campanha gaúcha, frente às áreas de produção agrícola, a Serra e o Planalto, resultaram, segundo Pedro Dutra Fonseca, do conflito entre dois planos econômicos propostos pelas facções em luta na República Velha. Para o autor, a meta dos republicanos era encontrar outras formas de incrementar a economia gaúcha, sem abandonar completamente a tradicional atividade pecuário-charquedora. Nesse sentido,

[...] em termos gerais, o plano republicano apóia-se na 
tentativa de diversificar a produção gaúcha, no intuito de resolver ou amenizar a crise por que passam as atividades econômicas tradicionais do Estado.

A principal característica da política econômica levada a efeito no período é tentar a criação de novas opções à economia do Rio Grande, e que significa, principalmente, dotar o Estado de uma sólida economia agrícola. Isto não significa que as autoridades governamentais tivessem uma postura antipecuarista (FONSECA, 1983, p. 72).

Todavia, a oposição não pensava da mesma forma. Para ela, o governo republicano relegava completamente a Campanha, área considerada imprescindivel para o desenvolvimento econômico gaúcho. Assim, esse conflito manteve-se ao longo dos anos; enquanto os chimangos, ou republicanos, fundamentavam sua diversidade agrícola a partir da decadência da pecuária, os maragatos, ou membros da oposição, argumentavam que nunca o Rio Grande fora tão próspero como no tempo do Império e que a crise de então era "fruto da atuação de Castilhos e Borges no campo econômico" (FONSECA, 1983, p. 76).

Na opinião de Sandra Pesavento,

[...] o governo gaúcho republicano de feição positivista que assumiu o poder político em 1889 tinha, pois, como programa de ação básica no campo econômico, a defesa de um modelo diversificado e integrado, onde os setores agrário e secundário se inter-relacionavam, dando ao estado um cunho moderno, progressista e de autossuficiência (PESAVENTO, 1992, p. 17).

Já na visão de Loiva Otero Félix,

A subida do grupo republicano ao poder (contrário a qualquer tipo de privilégio) determinou a execução de seu projeto político que consistia em ferir pontos chaves do pacto imperial (que privilegiava os estancieiros, os coronéis da fronteira sul) gerando, com isso, a 
necessidade de redefinição das relações sociopoliticas (FÉLIX, 1987, p. 53 - grifo original).

Esse apoio aos setores agrário e industrial decorria da inspiração na doutrina positivista do francês Auguste Comte, de maneira que "o progresso seria dado pelo desenvolvimento industrial, pelo primado da ciência, pela educação e pela moral" (PESAVENTO, 1992, p. 23). Nesse sentido, a ciência e a indústria garantiriam o progresso, e a educação e a moral manteriam a ordem social, já que um fator dependia diretamente do outro. Ou seja, sem ordem, não haveria progresso, e vice-versa.

Entretanto, essas máximas burguesas - ordem e progresso apresentavam incoerências na prática, já que, concebidas numa realidade europeia com um capitalismo já maduro, elas foram adaptadas para uma realidade regional muito distinta (Cf. PESAVENTO, 1992), onde o capitalismo industrial apenas começava a engatinhar. Por outro lado, não havia no Rio Grande do Sul uma atividade agrária de conotação capitalista que pudesse servir de base para a emergência de uma ordem urbano-industrial, ao contrário da pecuária e das charqueadas que há muito tempo representavam uma atividade capitalista e garantiam divisas para o estado. Mas o autoritarismo ilustrado preferia defender um modelo diversificado e integrado, através da inter-relação entre os setores agrário e secundário, para que o estado adquirisse um cunho moderno, progressista e autossuficiente.

Esse era, em suma, parte do cenário econômico, político e social dos primeiros anos da República Velha que foi vivenciado pelo escritor Simões Lopes Neto, e cujas reverberações são perceptíveis em sua obra. O que parece um simples deboche descompromissado da imaginação de um escritor em relação aos ilhéus e reinóis, e por tabela aos imigrantes alemães e italianos, e aos vizinhos platinos, é, na verdade, fruto de uma rivalidade muito antiga entre o gaúcho e todos os estrangeiros que vinham se instalar nas terras do Rio Grande. Como observa Chiappini (1988), os fazendeiros tratavam de desmoralizar os "outros" e de exaltar as qualidades do gaúcho tradicional, do peão que, por seu turno, sofria as transformações da estância, provocadas pela introdução e geração de novos produtos comercializáveis.

Ainda no âmbito da construção de uma identidade coletiva 
para os sul-rio-grandenses, através da formação da imagem dos amigos e inimigos, no conto "Contrabandista", Blau, o vaqueano-narrador, explica que

nesta terra do Rio Grande sempre se contrabandeou, desde em antes da tomada das Missões. Naqueles tempos o que se fazia era sem malícia, e mais por divertir e acoquinar as guardas do inimigo: uma partida de guascas montava a cavalo, entrava na Banda Oriental e arrebanhava uma ponta grande de eguariços; abanava o poncho e vinha a meia-rédea; apartava-se a potrada e largava-se o resto; os de lá faziam conosco a mesma coisa; depois era com gados [...] (LOPES NETO, 1988, p. 100).

E é importante destacar que "isso se fazia por despique dos espanhóis e eles pagavam desquitando-se do mesmo jeito” (LOPES NETO, 1988, p. 100). Ou seja, depreende-se que se tratava de um contrabando sem malícia, por desforra, por divertimento.

Todavia, segundo o narrador, após a Guerra dos Farrapos e da guerra contra o ditador argentino Rosas, em 1852, a conjuntura histórica se modifica:

Aí inundou-se a fronteira da província de espanhóis e gringos emigrados. [...] A estrangeirada era mitrada, na regra, e foi quem ensinou a gente de cá a mergulhar $\mathrm{e}$ ficar de cabeça enxuta...; entrou nos homens a sedução de ganhar barato: bastava ser campeiro e destorcido (LOPES NETO, 1988, p. 101).

Eis aí, novamente, o estrangeiro, o rival e inimigo castelhano a trazer a corrupção para o Rio Grande, destruindo o caráter quase lúdico do contrabando.

Nesse contexto, assoma a figura de Jango Jorge, o gaúcho folgazão, desleixado, mão-aberta, conhecedor de todos os recantos do Rio Grande e contrabandista desde a juventude. Na véspera do casamento da filha, ele sai para buscar o enxoval: "Aonde, não sei; parecia-me que aquilo devia ser feito em casa, à moda antiga, mas, como cada um manda no que é seu..." (LOPES NETO, 1988, p. 100). 
Todavia, Jango Jorge é morto pela guarda, quando tentava passar a fronteira trazendo o vestido da noiva. Sua história remete ao gaúcho corrompido pelo luxo, pelo esbanjamento e ostentação de bens estrangeiros, condição condenada por Blau Nunes, o representante dos valores e costumes gaúchos tradicionais.

O final do conto, por sua tragicidade, pode ser lido, ao mesmo tempo, como advertência e metáfora da degradação tanto dos valores genuínos quanto do território gaúcho, provocada pela interferência estrangeira:

[...] era o vestido branco da filha, os sapatos brancos, o véu branco, as flores de laranjeira... Tudo numa plastada de sangue... tudo manchado de vermelho, toda a alvura daquelas coisas bonitas como que bordada de colorado, num padrão esquisito, de feitios estrambólicos... como flores de cardo solferim esmagadas a casco de bagual!... (LOPES NETO, 1988, p. 103).

A análise dessa série de exemplos extraídos dos Contos gauchescos e Lendas do Sul possibilita observar, principalmente por parte da personagem Blau Nunes, o esforço pela ereção de uma identidade fortemente caracterizada pela ideia de sacralização, ou seja, de união da comunidade sul-rio-grandense em torno de seus usos, costumes e tradições. Em decorrência disso, açorianos, reinóis, castelhanos, ingleses e mouros são desabonados e até expulsos do território sul-rio-grandense, posto que carregam consigo a fraqueza, a covardia, a traição e a maldade, atributos que se contrapõem aos do gaúcho herói.

Inserido em um contexto histórico marcado pelo nacionalismo, Simões Lopes, sem deixar de ser regionalista, pretendeu agregar o Rio Grande do Sul ao Brasil - ideal que transparece de modo especial no conto "Chasque do Imperador", no qual, após um escancarado deboche, o monarca abre mão da pompa e dos doces e põe-se a digerir um típico churrasco gaúcho. Nessa troca simbólica, do imperador "tornando-se" gaúcho e do gaúcho servindo-o, ou seja, cumprindo ordens e dando o pelego, como diria Blau, emerge plenamente a integração da região à nação. Em outros termos, o Brasil, representado na figura do Imperador, é aceito pelo gaúcho, e o Rio Grande do Sul, por sua vez, com seus hábitos e costumes, não só é aceito pelo Brasil, 
como também passa a servi-lo na figura de Blau, o ordenança que cumpre ordens. É o encontro, finalmente, entre o Rio Grande do Sul e o Brasil.

A identidade cultural regional buscada nos Contos gauchescos e Lendas do Sul, especialmente por parte do personagem-narrador Blau Nunes, desmoraliza e rechaça, em suma, a presença de qualquer aspecto estrangeiro que possa interferir no meio econômico, político e social do Rio Grande do Sul, como o contrabando lucrativo, a cobiça e a ganância. Inclusive os indivíduos que não se enquadram nos atributos do gaúcho heroico, ou seja, aqueles que não se identificam física e moralmente com o habitante nativo, são notadamente depreciados pelo narrador, como acontece com açorianos, reinóis, castelhanos e, em certa medida, com paulistas e baianos.

\section{REFERÊNCIAS}

BERND, Zilá. Literatura e identidade nacional. Porto Alegre: Editora da Universidade/UFRGS, 1992, p.17 (Col. Síntese Universitária 36).

CHAVES, Flávio. Loureiro. Simões Lopes Neto: regionalismo \& literatura. Porto Alegre: Mercado Aberto, 1982 (Documenta 12).

CHIAPPINI, Ligia. No entretanto dos tempos: literatura e história em João Simões Lopes Neto. São Paulo: Martins Fontes, 1988.

FÉLIX, Loiva Otero. Coronelismo, borgismo e cooptação política. Porto Alegre: Mercado Aberto, 1987 (Documenta 23).

FONSECA, Pedro C. Dutra. RS: economia E conflitos políticos na República Velha. Porto Alegre: Mercado Aberto, 1983, pp.17-18 (Documenta 18).

FRANCO, Sérgio da Costa. Júlio de Castilhos e sua época. 2.ed., Porto Alegre: Editora da Universidade/UFGRS, 1988.

LOPES NETO, João Simões. Contos gachescos, Lendas do Sul, Casos do Romualdo. Edição crítica por Ligia Chiappini. Rio de Janeiro: Presença; Brasília: INL, 1988. 
NUNES, Zeno Cardoso; NUNES, Rui Cardoso. Dicionário de Regionalismos. Porto Alegre: Martins Livreiro, 1982.

PESAVENTO, Sandra J. O cotidiano da república. 2.ed., Porto Alegre: Editora da Universidade/UFRGS, 1992, p.17 (Síntese RioGrandense).

STÜBEN, Jens. Literatura regional e literatura na região. In: ARENDT, João Claudio; NEUMANN, Gerson Roberto. (Orgs.). Regionalismus - regionalismos: subsídios para um novo debate. Caxias do Sul: EDUCS, 2013.

WOODWARD, Kathryn. Identidade e diferença: uma introdução teórica e conceitual. In: SILVA, Tomaz Tadeu da; HALL, Stuart; WOODWARD, Kathryn. Identidade e diferença: a perspectiva dos estudos culturais. 4.ed. Petrópolis, RJ: Vozes, 2005.

Recebido em: 03/07/2016

Aceito em: 22/07/2016 